RESEARCH

\title{
KNOWLEDGE, ATTITUDES AND BEHAVIOURS OF ELDERLY PEOPLE LIVING AT A NURSING HOME RELATED TO PNEUMOCOCCAL AND INFLUENZA VACCINES
}

Turkish Journal of Geriatrics

DOI: 10.31086/tigeri.2021.223

2021; 24(2): 264-275

- Handan ATSIZ SEZIK ${ }^{1}$

- Nil TEKIN ${ }^{2}$

CORRESPONDANCE

${ }^{1}$ Handan ATSIZ SEZiK

Ministry of Health, Urla 3 rd M.F. Ikbal Mahmut

Kircali Family Healty Center, Family Medicine

Center, Izmir, Turkey

Phone: +905059442334

e-mail: sezikhandan@gmail.com

Received: Jan 15, 2021

Accepted: Apr 04, 2021

${ }^{1}$ Ministry of Health, Urla 3 rd M.F. Ikbal Mahmut Kircali Family Healty Center, Family Medicine Center, Izmir, Turkey

${ }^{2}$ Narlidere Nursing Home Elderly Care and Rehabilitation Center, Family Medicine, Izmir, Turkey

\section{Abstract}

Introduction: The World Health Organization declared the COVID-19 outbreak a pandemic on March 11, 2020; since then, protecting the elderly against infections through immunisation has become increasingly critical. This study aims to assess the knowledge level of individuals aged 65 years and above at a nursing home who are in the risk group for pneumococcal and influenza vaccines along with their attitudes and behaviours regarding immunisation.

Materials and Methods: The questionnaire prepared by the researcher was administered to the elderly residents aged 65 years and above who could perform their own self-care in the blocks designated for healthy residents at the Narlidere Nursing Home Elderly Care and Rehabilitation Center after obtaining their oral consent.

Results: The average age of the 708 elderly residents who participated in the research was $79.05 \pm 7.32$ years (range 62-98), and 63\% were female. Of the residents, $75.1 \%$ had heard about the pneumococcal vaccine, and $97.2 \%$ were aware of the influenza vaccine. Only $24.6 \%$ had been administered the pneumococcal vaccine, and $29.9 \%$ expressed that they did not receive it because their physician did not recommend it. A significant relation was found between having received the pneumococcal vaccine and age group $(p=0.046)$ and having received the pneumococcal vaccine and educational background $(p=0.025)$.

Conclusion: Elderly people have more knowledge about influenza vaccine than pneumococcal vaccine. Their healthcare professionals mostly inform them about vaccinations. Therefore healthcare professionals should be trained about the pneumococcal vaccination procedures in elderly.

Keywords: Aged; Influenza Vaccines; Pneumococcal Vaccines; Nursing Homes 


\section{INTRODUCTION}

There is clear evidence that the average age of the world's population is rising. In Turkey, the number of individuals who are 65 years of age and above has increased by $21.9 \%$ over the past five years (1). Thus, healthy ageing of the population is increasingly important. The main factor contributing to healthy ageing is the practice of protection. Reports indicate that pneumococcal disease and influenza are the leading causes of mortality and morbidity associated with diseases that can be prevented by immunisation in the elderly (2). Immunisation is the easiest, most economical and most strategic method for infectious disease protection in both elderly individuals and children.

Aged people are vulnerable to diseases because of changes in the immune system, and even simple upper respiratory infections may have serious consequences (2). Immune system changes in the elderly include a decrease in immunological functions and the deterioration of immune regulation as a person ages (3). Accordingly, the incidence and mortality of pneumococcal disease in individuals 65 years of age and above have significantly increased (4). Analysis of data from the Turkish Statistical Institute reveals that respiratory system diseases were, with a rate of $14.8 \%$, the third-highest cause of mortalities in individuals aged 65 years and above in 2018 (5).

Influenza viruses cause acute respiratory tract infections and vary in presentation from mild clinical symptoms to severe infections that may result in mortality (6). The elderly exhibit respiratory insufficiency with influenza at a rate that is 10-30 times higher than in young people (4). According to data from the Centers for Disease Control and Prevention (CDC), of the approximately 31,000 deaths due to COVID-19, pneumonia and influenza infections between February and September 2020, 79\% involved patients aged 65 years and above $(7,8)$.

The World Health Organization (WHO) has identified "Streptococcus pneumonia" and seasonal influenza amongst those respiratory tract infections that may be the most significant causes of hospitalisation and mortality in aged people which can be prevented by immunisation. At the global level, the medical community has reported a very high mortality rate of COVID-19, which emerged in December 2019, in the aged population. However, the clinical findings are unclear, atypical and not specific to the disease. The need to minimise other respiratory tract infections has become increasingly urgent in view of the mortality rate of COVID-19 pneumonia in the aged population. Accordingly, there has been an increase in the importance of pneumococcal and influenza vaccines as well as amplified social interest $(9,10)$. Living at a residential facility or nursing home and being 65 years of age or older are main risk factors for pneumococcal disease and influenza (11). Thus, the aim of this study is to determine the knowledge level of individuals aged 65 years and above at a nursing home who are in the risk group with respect to pneumococcal and influenza vaccines and to assess their attitudes and behaviours regarding immunisation.

\section{MATERIALS AND METHOD}

The research design entails a cross-sectional questionnaire study. The questionnaire form was administered to individuals aged 65 years and above who were living in the blocks for healthy residents at the Izmir/Narlidere Nursing Home Elderly Care and Rehabilitation Center. The respondents had to be able to manage their own care and daily life activities without assistance from others, and their participation was approved after the researchers obtained their oral consent via a face-to-face interview method between the dates of May 2016 and January 2017.

The researchers prepared a questionnaire form that contained 14 items covering the demographical characteristics of the participants, including their age, sex, educational background, and marital status, the presence of disease, their knowledge of 
pneumococcal and influenza vaccines, whether they had been informed about the vaccines by healthcare professionals, whether such information was sufficient, their immunisation status, information about payment for vaccines by the social security institution, and their reasons for not receiving the vaccines (Table 1). The study was conducted with consideration to the number of elderly residents who were on leave in the summer. As of January 2017, all elderly residents of the blocks for the healthy at the nursing home had been contacted.

\section{Statistical Analysis}

The dependent variables were vaccination status and knowledge and attitudes of pneumococcal and influenza vaccines in the elderly, while the independent variables were sex, age group, marital status, educational background and presence of disease. The obtained data were processed on a computer and evaluated with the Statistical Package for Social Sciences (SPSS) version 18.00. Group comparisons were performed using the chi-squared test for categorical variables, and significance was defined as $\mathrm{p}<0.05$.

\section{Ethical Considerations}

The study was initiated after securing approval from the ethical committee of Izmir Katip Celebi University (no. 110, dated 26.05.2016) along with the consent of the relevant ministries and institutions. All participants were literate, and they were informed about the study before they provided oral consent. The researchers distributed the questionnaires and monitored the process, and the participants filled out the questionnaire forms independently at the health offices, in common living spaces or in their rooms.

\section{RESULTS}

Of the 746 elderly residents of the unsupported living blocks in the nursing home, 708 residents who had not been diagnosed with dementia agreed to participate in the study. Of these 708 participants, $63.1 \%$ were female $(n=447)$, and the average age was $79.05 \pm 7.32$ years (range 62-98). The distribution of each age range was as follows: 190 (26.8\%) participants were 65-74 years of age, 329 (46.5\%) were $75-84$ years of age and 189 (26.7\%) were aged 85 or older. In addition, 218 (30.8\%) participants had completed primary and secondary school, 263 (37.1\%) were high school graduates and 227 (32.1\%) held university degrees.

A chronic disease was reported by $81.6 \%$ of the participants. Specifically, 354 (50\%) identified hypertension (HT), 169 (23.9\%) reported diabetes mellitus (DM), 124 (17.5\%) had coronary artery disease (CAD), 118 (16.7\%) identified congestive heart failure, 77 (10.9\%) experienced chronic obstructive pulmonary disease (COPD) and 51 (7.2\%) reported obesity. Amongst the participants, 397 (56.1\%) had been informed about the payment status of the vaccines by the social security institution.

A total of 532 (75.1\%) participants had heard about the pneumococcal vaccine. Twenty-five (3.5\%) elderly patients had contracted pneumonia in the most recent year, while 174 (24.6\%) of the elderly residents had received the pneumococcal vaccine.

With regard to reasons for not receiving the pneumococcal vaccine, 212 (29.9\%) of the elderly participants indicated that their physician did not recommend it, 148 (20.9\%) stated that they had not heard about the vaccine, 68 (9.6\%) reported that they were healthy, $63(8.9 \%)$ did not believe that it was effective and $5(0.7 \%)$ had been unable to find the vaccine. Of the elderly participants who had received the vaccine, 17 (10.2\%) expressed that they had acquired pneumonia despite being vaccinated. No significant relation was found between the presence of chronic disease and having received the pneumococcal vaccine $(p>0.05)$. Significant relations were found between the age group ( $p=$ $0.046)$ and educational background ( $p=0.025)$ and having received the pneumococcal vaccine, but no 
Table 1. Questionnaire form

\begin{tabular}{|c|c|c|c|c|c|}
\hline \multicolumn{6}{|c|}{$\begin{array}{l}\text { Knowledge, behavior and attitudes of the individuals aged 65-year and above living at the nursing home related to the pneu- } \\
\text { mococcal and influenza vaccine }\end{array}$} \\
\hline \multirow{2}{*}{ Line } & \multicolumn{2}{|l|}{ Questionnaire questions } & & & \\
\hline & Age & & & & \\
\hline 2 & Sex & & $\square$ female & $\square$ male & \\
\hline 3 & Marital status & $\square$ single & $\square$ married & $\square$ widow & $\square$ divorced \\
\hline 4 & Educational background & $\square$ primary school & $\square$ secondary school & $\square$ high school & $\square$ university \\
\hline & & $\square$ higher education & $\square$ literate & $\square$ not literate & \\
\hline 5 & Do you have any known disease? & $\square$ no & $\square$ yes & $\square$ if yes, indicate & \\
\hline 6 & $\begin{array}{l}\square \mathrm{DM} \square \mathrm{HT} \quad \square \mathrm{CAD} \square \mathrm{CRD} \square \mathrm{COPD} \square \mathrm{CLD} \square \\
\text { Obesity } \square \text { Other }\end{array}$ & & & & \\
\hline 7 & $\begin{array}{l}\text { Did you hear about pneumococcal and influen- } \\
\text { za vaccine? }\end{array}$ & $\square$ no & $\square$ yes & $\square$ if yes, where? & \\
\hline 8 & $\begin{array}{l}\square \text { tv } \square \text { radio } \square \text { internet } \square \text { press } \square \text { friends } \square \text { family } \\
\square \text { healthcare professional }\end{array}$ & & & & \\
\hline 6 & $\begin{array}{l}\text { Do you think that information is sufficient if you } \\
\text { informed by the healthcare professional? }\end{array}$ & $\square$ no & $\square$ yes & $\square$ partly & \\
\hline 7 & Did you get pneumococcal vaccine? & $\square$ no & $\square$ yes & $\square$ if yes, when & \\
\hline 8 & Did you get influenza vaccine? & $\square$ no & $\square$ yes & $\square$ if yes, when & \\
\hline 9 & Did you get another vaccine? & $\square$ no & $\square$ yes & $\square$ if yes, indicate & \\
\hline 20 & $\begin{array}{l}\text { Do you know that vaccine cost is covered } \\
\text { by the social security institution for chronic } \\
\text { diseases? }\end{array}$ & $\square$ no & $\square$ yes & & \\
\hline 11 & $\begin{array}{l}\text { Have you had pneumonia or influenza in recent } \\
\text { year? }\end{array}$ & $\square$ no & $\square$ yes & & \\
\hline 12 & $\begin{array}{l}\text { Reason of not getting vaccine? (You may } \\
\text { choose more than one options for the answers } \\
\text { of these questions) }\end{array}$ & & & & \\
\hline $12-\mathrm{A}$ & Reason of not getting pneumococcal vaccine? & & & & \\
\hline 12.A.1 & I didn't hear about pneumococcal vaccine. & $\square$ & & & \\
\hline 12.A.2 & I don't believe it is efficient & $\square$ & & & \\
\hline 12A.3 & I could not find the vaccine & $\square$ & & & \\
\hline 12.A.4 & My physician did not recommend it & $\square$ & & & \\
\hline 12.A.5 & I believe that it has side effects. & $\square$ & & & \\
\hline 12.A.6 & I had problems when I had got it before. & $\square$ & & & \\
\hline 12.A.7 & I have never had lung disease in my life & $\square$ & & & \\
\hline 12.A.8 & I am a healthy person, therefore I don't get it & $\square$ & & & \\
\hline $12 . \mathrm{B}$ & Reason of not getting the influenza vaccine & & & & \\
\hline 12.B.1 & I didn't hear about influenza vaccine. & $\square$ & & & \\
\hline 12.B.2 & I don't believe it is efficient & $\square$ & & & \\
\hline 12.B.3 & I could not find the vaccine & $\square$ & & & \\
\hline 12.B.4 & My physician did not recommend it & $\square$ & & & \\
\hline 12.B.5 & I believe that it has side effects. & $\square$ & & & \\
\hline 12.B.6 & I had problems when I had got it before. & $\square$ & & & \\
\hline 12.B.7 & I have never had influenza in my life & $\square$ & & & \\
\hline 12.B.8 & I am a healthy person, therefore I don't get it & $\square$ & & & \\
\hline 13 & $\begin{array}{l}\text { Did you have pneumonia even if you got pneu- } \\
\text { mococcal vaccine? }\end{array}$ & $\square$ no & $\square$ yes & & \\
\hline 14 & $\begin{array}{l}\text { Have you had influenza in recent year even if } \\
\text { you got influenza vaccine? }\end{array}$ & $\square$ no & $\square$ yes & & \\
\hline
\end{tabular}


significant relation was identified for sex or marital status (Table 2).

Twenty (2.8\%) participants indicated that they had not heard about the influenza vaccine. There was a statistically significant difference $(p=0.00)$ between the rate of awareness of the influenza vaccine (97.2\%) versus of the pneumococcal vaccine $(75.1 \%)$ amongst the participants. While 281 (39.7\%) participants reported that they had contracted influenza in the most recent year, 419 (59.2\%) had received influenza vaccine. In terms of reasons for not receiving the influenza vaccine, 111 (15.7\%) of the participants did not believe that it was effective, 76 (10.7\%) indicated that their physician did not recommend it, 67 (9.5\%) stated that they were healthy and $3(0.4 \%)$ explained that they had not been able to find the vaccine. Of the individuals who had received the vaccine, $50.5 \%$ indicated that they had acquired influenza despite being vaccinated. No significant relation was found between sex, age group, marital status or educational status of the participants and having received a vaccination $(p>0.05)$. (Table 2$)$

Of the participants, 149 (21.0\%) had received both the pneumonia and the influenza vaccines, while 264 (37.3\%) had not received both vaccines. No significant relation was found between sex, age group, marital status or educational status of the participants and having received the pneumococcal and influenza vaccines ( $p>0.05)$. Table 2 details the characteristics of the patients who had received both the pneumococcal and influenza vaccines.

Some of the participants had received other vaccines; for example, 25 (3.5\%) had received the tetanus vaccine, and $11(1.5 \%)$ had received the rabies vaccine. A total of 364 (51.4\%) participants had been made aware of the pneumococcal vaccine by healthcare professionals, while 135 (19\%) had heard about it from television. Likewise, 528 (74.5\%) participants had been informed about the influenza vaccine by healthcare professionals, whereas 174 (24.5\%) had heard about it from television. Figure 1 specifies the sources from which the participants had heard about the pneumococcal and influenza vaccines.

\section{DISCUSSION}

A few studies have investigated the knowledge, attitudes and behaviours of elderly residents in the community towards influenza and pneumococcal vaccines in Turkey. However, the present study is the first on this subject amongst elderly nursing home residents in our country. Notably, the data were obtained from the highest-capacity residential and nursing home and rehabilitation centre in the country, and almost all occupants of the blocks for healthy residents participated in the study.

Of the 708 elderly residents who participated in the study, $63 \%$ were female; however, $63 \%$ of the elderly residents of the state-affiliated institutional nursing home in Turkey are male. In addition, high school or equivalent graduates account for $5.9 \%$ of the population above the age of 65 , and the rate of individuals with higher education is $5.8 \%$ (12). Although the average age of the participants was high at approximately 80 , about $70 \%$ of them reported a high school or university education. A possible explanation for this finding is that they or their family members had retired from official duty for the state. These demographic data reflect that the study was carried out in an institutional nursing area amongst a female, age-weighted population with relatively high levels of education and socioeconomic status.

Chronic disease heightens the risk of infection for elderly residents of a nursing home. Of the $81.6 \%$ of participants who stated that they had a chronic disease, $50 \%$ identified the presence of $\mathrm{HT}$, and $23.9 \%$ reported experiencing DM. In the literature, the most prevalent type of chronic disease is $\mathrm{HT}$, which exhibits a rate of $38.5-48.4 \%$ in nursing homes, while the same rate is $18.2 \%-26.4 \%$ for DM (13).

In the present study, $75.1 \%$ of the elderly participants at the nursing home stated that they had 
Table 2. Status of getting pneumococcal and influenza vaccine of the participants by the characteristics

\begin{tabular}{|c|c|c|c|c|}
\hline Characteristics & $n(\%)$ & $n(\%)$ & $n(\%)$ & $P$ \\
\hline & Vaccinated & Unvaccinated & Total & \\
\hline \multicolumn{5}{|l|}{ Sex } \\
\hline \multicolumn{5}{|l|}{ Pneumococcal vaccine } \\
\hline Female & $119(26,6)$ & $328(73,4)$ & $447(100)$ & 0.098 \\
\hline Male & $55(21,1)$ & $206(78,9)$ & $261(100)$ & \\
\hline \multicolumn{5}{|l|}{ Influenza vaccine } \\
\hline Female & $254(56,8)$ & $193(43,2)$ & $447(100)$ & 0.095 \\
\hline Male & $165(63,2)$ & $96(36,8)$ & $261(100)$ & \\
\hline \multicolumn{5}{|c|}{ Pneumococcal and Influenza vaccine } \\
\hline Female & $98(36,8)$ & $172(63,7)$ & $270(100)$ & \\
\hline Male & $51(35,7)$ & $92(64,3)$ & $143(100)$ & 0.952 \\
\hline \multicolumn{5}{|l|}{ Age } \\
\hline \multicolumn{5}{|l|}{ Pneumococcal vaccine } \\
\hline $65-74$ & $9(20,5)$ & $51(79,5)$ & $190(100)$ & \\
\hline 75-84 & $95(28,9)$ & $234(71,1)$ & $329(100)$ & $0.046^{*}$ \\
\hline $85+$ & $40(21,2)$ & $149(78,8)$ & $189(100)$ & \\
\hline \multicolumn{5}{|l|}{ Influenza vaccine } \\
\hline $65-74$ & $107(56,3)$ & $83(43,7)$ & $190(100)$ & \\
\hline $75-84$ & $197(59,9)$ & $132(40,1)$ & $329(100)$ & 0.628 \\
\hline $85+$ & $115(60,8)$ & $74(39,2)$ & $189(100)$ & \\
\hline \multicolumn{5}{|l|}{ Pneumococcal and Influenza vaccine } \\
\hline $65-74$ & $31(29,2)$ & $75(70,8)$ & $106(100)$ & \\
\hline $75-84$ & $81(40,7)$ & $118(59,3)$ & $199(100)$ & 0.113 \\
\hline $85+$ & $37(34,3)$ & $71(65,7)$ & $108(100)$ & \\
\hline \multicolumn{5}{|l|}{ Marital status } \\
\hline \multicolumn{5}{|l|}{ Pneumococcal vaccine } \\
\hline Single & $26(32,1)$ & $55(67,9)$ & $81(100)$ & \\
\hline Married & $67(24)$ & $212(76)$ & $279(100)$ & 0.242 \\
\hline Widow/Divorced & $81(23,3)$ & $267(76,7)$ & $348(100)$ & \\
\hline \multicolumn{5}{|l|}{ Influenza vaccine } \\
\hline Single & $48(59,3)$ & $33(40,7)$ & $81(100)$ & \\
\hline Married & $175(62,7)$ & $104(37,3)$ & $279(100)$ & 0.269 \\
\hline Widow/Divorced & $196(56,3)$ & $152(43,7)$ & $348(100)$ & \\
\hline
\end{tabular}




\begin{tabular}{|c|c|c|c|c|}
\hline \multicolumn{5}{|l|}{ Pneumococcal and Influenza vaccine } \\
\hline Single & $21(42,9)$ & $28(57,1)$ & $49(100)$ & \\
\hline Married & $61(38,4)$ & $98(61,6)$ & $159(100)$ & 0.476 \\
\hline Widow/Divorced & $67(32,7)$ & $138(67,3)$ & $205(100)$ & \\
\hline \multicolumn{5}{|l|}{ Educational background } \\
\hline \multicolumn{5}{|l|}{ Pneumococcal vaccine } \\
\hline Literate/not literate, primary school & $25(19,4)$ & $104(80,6)$ & $129(100)$ & \\
\hline Secondary school & $26(29,2)$ & $63(70,8)$ & $89(100)$ & $0.025^{*}$ \\
\hline High school & $54(20,5)$ & $209(79,5)$ & $263(100)$ & \\
\hline Higher education & $69(30,4)$ & $158(69,6)$ & $227(100)$ & \\
\hline \multicolumn{5}{|l|}{ Influenza vaccine } \\
\hline Literate/not literate, primary school & $70(54,3)$ & $59(45,7)$ & $129(100)$ & \\
\hline Secondary school & $58(65,2)$ & $31(34,8)$ & $89(100)$ & 0.105 \\
\hline High school & $146(55,5)$ & $117(44,5)$ & $263(100)$ & \\
\hline Higher education & $145(63,9)$ & $82(36,1)$ & $227(100)$ & \\
\hline \multicolumn{5}{|l|}{ Pneumococcal and Influenza vaccine } \\
\hline Literate/not literate, primary school & $22(28,2)$ & $56(71,8)$ & $78(100)$ & \\
\hline Secondary school & $24(45,3)$ & $29(54,7)$ & $53(100)$ & 0.014 \\
\hline High school & $45(29,4)$ & $108(70,6)$ & $153(100)$ & \\
\hline Higher education & $58(45,0)$ & $71(55,0)$ & $129(100)$ & \\
\hline
\end{tabular}

heard about the pneumococcal vaccine, and $24.6 \%$ had received that vaccine. In a study by Erdogdu et al., which was conducted at an elderly living facility in Kars, 26.9\% of the 543 participants were aware of the pneumococcal vaccine, but only five of them had received it. This study suggested that educational level and low economic income affected knowledge about the vaccine and immunisation (14). Additionally, in research by Baig et al., $79.5 \%$ of the elderly participants who recorded high socioeconomic and educational levels had heard about the pneumococcal vaccine, whereas this figure was only $28.8 \%$ amongst those with low socioeconomic and educational levels. In the same study, the immunisation rate was $16.5 \%$ for the former group but only 2.3\% for the latter (15).

Participants had heard about and received the pneumococcal vaccine at significantly higher rates in the present study compared to in other studies in the context of Turkey. While the rate of awareness of the pneumococcal vaccine was congruent with the rate in a study of a high socioeconomic group of elderly participants in Pakistan, the immunisation rates were slightly higher in our study. These results are supported by the statistically significant relations between the age groups and educational background of our research participants and having received the pneumococcal vaccine.

In a study by Kohlhammer et al., a recommendation from a physician and recognition of the pneumococcal vaccine were the main determinants of receiving the pneumococcal vaccine. Other reported determinants were chronic diseases, advanced age, high educational level and pneumonia (16). 
Figure 1. Sources that participants heard about pneumococcal and influenza vaccine

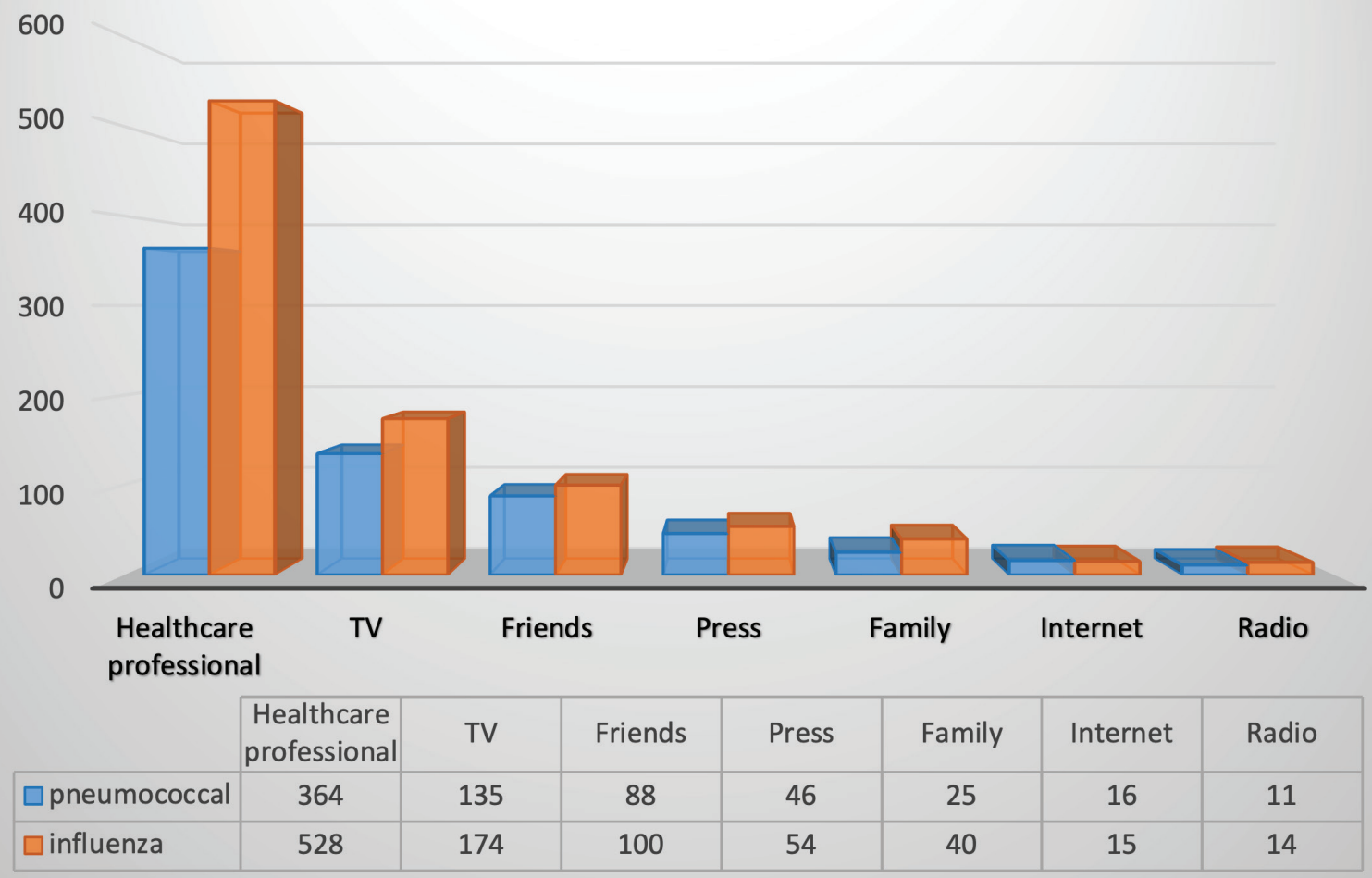

While the present study has identified a significant relation between age group and educational level and the condition of immunisation, no relation with chronic diseases was found. According to research by Schneeberg et al., in Canada, the rate of pneumococcal vaccination was $58 \%$, and the strongest factor for vaccination was a recommendation from a healthcare professional (17). In the present study, the most frequently cited reason for not receiving the pneumococcal vaccine was that 'my physician did not recommend it'. The other reasons were that 'I have not heard about the pneumococcal vaccine' and 'I am healthy'. In the study by Erdogdu et al., only $15.1 \%$ of the participants stated that they would not receive the vaccine even if it had been recommended by a physician; other reasons for not receiving the vaccine included a fear of the side effects, good health, old age and not being old enough (14). Based on our study with the elderly residents of the nursing home, it is evident that the most important obstacle to receiving the pneumococcal vaccine can be overcome by encouraging physicians to recommend the vaccine. This conclusion is consistent with the implications of prior studies amongst elderly individuals who were living in the larger society.

Our study registered a statistically significant difference between the rate of awareness of the influenza vaccine versus of the pneumococcal vaccine. Although $97.9 \%$ of the participants had heard 
about the influenza vaccine, only $59.2 \%$ had been vaccinated. The differences between the various sociodemographic factors and having received the influenza vaccine were not statistically significant. In the study by Erdogdu et al., which was performed with elderly individuals who were living in society, $52.7 \%$ of the participants had heard about the influenza vaccine, while approximately $12 \%$ had received it (14). In research by Gazibara et al., $92.4 \%$ of the participants recorded scores ranging from good to very good for their knowledge levels regarding influenza, yet the vaccination rate was found to be $47.7 \%$ (18). Research by Polat et al. in Antalya determined that $55.7 \%$ of the individuals aged 65 years and above who were living in society were aware of the influenza vaccine, but only $15 \%$ of them had received it (19). Finally, in a study by Ciblak et al. in Turkey, the rate of having received the influenza vaccine was $5.9 \%$ (6), and Yigitbas et al. similarly noted that $22 \%$ of elderly applicants to the hospital had been vaccinated against influenza (20). In our study, the rates of vaccination amongst the elderly were notably higher than those reported by numerous studies in other countries as well as in Turkey.

In the present study, reasons for not receiving the influenza vaccine included a belief that it was not effective, a lack of recommendation from a physician and a self-perception of good health that rendered the vaccine unnecessary. In the study by Gazibara et al., the participants cited similar reasons, such as being healthy, not needing the vaccine and not believing that it would provide protection against the flu (18). Ciblak et al. specified that the most frequent reason in their research was that 'the vaccine is not effective', though, similarly to in our study, other reasons included that 'the vaccine will cause influenza' and 'influenza can be treated' (6). In another study by Yigitbas et al., the first three reasons for not receiving the vaccine were that the participants had not been informed about the influenza vaccine, they did not feel that they needed it and they did not believe in its efficiency (10.9\%). Those researchers also observed that the provision of advice to the elderly by physicians had an influence on vaccination (20).

In a study of elderly people living in the community in Turkey, only 3 of the 543 participants had received both the pneumococcal and influenza vaccines (14). Meanwhile, in our study, $21 \%$ of the participants had received both the pneumococcal and influenza vaccines. It is noteworthy that this rate is remarkably high compared to data from the national level. In 2021, given the increase in awareness during the COVID-19 pandemic, vaccination rates are being considered throughout the country. Therefore, it is likely that new studies are needed.

In Europe as a whole, the WHO has achieved the goal of a $75 \%$ vaccination rate in only the Netherlands and the United Kingdom; in some countries, such as Lithuania, Estonia and Bosnia-Herzegovina, rates remain below 5\% (21). Generally, apart from the most frequent reason (that a physician did not recommend it), all reasons for not receiving the vaccine concern individual attitudes and behaviours. However, these attitudes and behaviours can be changed by healthcare professionals (20). In a study by Unal et al., a one-day training was provided to family physicians in Denizli, Turkey; after eight months of administering the pneumococcal vaccine to individuals 65 years of age and above, the vaccination rate reached $60 \%$ (22). Thus, adult vaccination rates could be improved by providing training to family physicians in countries that have strong, widespread family physician practices.

In the National Vaccine Workshop that was held in Ankara in 2014, it was noted that, amongst adults, there is limited knowledge of diseases that could be prevented by vaccination as well as of the vaccines themselves. Furthermore, physicians possess limited knowledge of adult vaccination and, even if they have been informed about it, have not developed the habit of immunisation themselves. The workshop concluded that social fear and doubt must be eliminated to encourage the vaccination of adults, and communication problems may also require resolution (23). 
Following healthcare professionals, media (mainly television) and friends were the most important sources of information for participants in our study. In addition to knowledge and training regarding the protection that vaccines can provide against seasonal influenza and pneumococcal infections, which may occur in winter, there has been intense interest in vaccines for COVID-19 in recent efforts to mitigate the pandemic. These expectations warrant careful consideration. It is assumed that, besides the guidance of healthcare professionals, media (mainly television) and communication with friends (digital or otherwise) have considerable effects, which the results of our study reflect. There is still scarce information available about potential interactions between pneumococcal and influenza vaccines and COVID-19, though it is known that the risk of pneumococcal infection increases, the pneumococcal vaccine can prevent both primary and secondary bacterial infections, and the unnecessary use of antibiotics may seasonally affect the clinical presentation of infection by occurring concomitantly with other viral infections. While countries with pneumococcal and influenza vaccination programmes for aged and high-risk individuals have taken action to combat the spread of COVID-19, the maintenance of these programmes for aged people is recommended. Hospitalisation for respiratory tract diseases caused by pneumococcus and influenza can be prevented through vaccination, which would increase the availability of ventilatory support equipment, medicines and healthcare professionals to treat COVID-19 patients.

\section{CONCLUSION}

Primary care physicians have the crucial role of efficiently and adequately informing the elderly to ensure their vaccination within the scope of the programme. During the COVID-19 pandemic period, vaccination of the elderly needs to continue, and education and knowledge levels amongst this population are central in facilitating this process. Media (especially television) appear to be highly influential in addition to the guidance of healthcare professionals, especially during the pandemic, and the demand for vaccines has increased in line with the conclusions of our study. Therefore, it is imperative to deliver accurate information through the media.

With respect to the data in the study, training sessions were conducted for the physicians and the elderly. The programme, which was realised between October 2017 and February 2018, was considered the first collective adult conjugated pneumococcal vaccine practice at a nursing home in Turkey. Within this period, free conjugated pneumococcal vaccines were supplied by the provincial public health directorate, and the vaccine was administered to the elderly residents of the nursing home, who consented based on the indications. This vaccination programme exemplifies practical use of the conclusions of scientific studies to improve societal conditions, and the introduction of this programme prior to the pandemic process was significant. The growing public interest in conjugated pneumococcal vaccines in addition to influenza vaccines during the pandemic is essential to the success of this practice, as is informing physicians about measures for making adult vaccines as accessible as paediatric vaccines (e.g. by offering them at no cost). Elderly people have more knowledge about influenza vaccine than pneumococcal vaccine. Their healthcare professionals mostly inform them about vaccinations. Therefore healthcare professionals should be trained about the pneumococcal vaccination procedures in elderly.

\section{LIMITATIONS}

Our study presents the general limitations of a questionnaire study, and the conclusions are founded on the answers from the participants. The study was carried out at a nursing home amongst individuals with high levels of education and sociocultural status in the mid-upper income group. Thus, the findings do not reflect the entire elderly population. 


\section{REFERENCES}

1. The Information Source of Turkey. Data Portal. Seniors with statistics; 2019. [Internet]. Available from: https://data.tuik.gov.tr/Bulten/Index?p=Istatistiklerle-Yaslilar-2019-33712. Accessed: 05.10.2020.

2. Zeybek Y, Tokalak I, Boyacioglu S. Vaccination in the sixty-five and over age adults. Turkish Journal of Geriatrics 2004; 7(3): 152-154. (in Turkish)

3. VO Avkan. Infectious Diseases in Old Age, In: Yeşim G. Kutsal (Ed). New horizons in physical medicine and rehabilitation elderly healthy. 1th edition, Gunes Medical Bookstores, Turkey 2010, pp 279-91. (in Turkish)

4. Infectious Diseases and Clinical Microbiology Speciality Society of Turkey. Immunization working group. Adult immunization guide; 2019. [Internet]. Avaliable from: https://www.ekmud.org.tr/emek/rehberler/1-ekmud-rehberleri. Accessed: 05.10.2020.

5. The Information Source of Turkey. Data Portal. Death and cause statistics; 2019. [Internet] Available from: https://data.tuik.gov.tr/Bulten/Index?p=Istatistiklerle-Yaslilar-2019-33712. Accessed: 05.10.2020.

6. Ciblak MA, Grip Platformu. Influenza vaccination in Turkey: prevalence of risk groups, current vaccination status, factors influencing vaccine uptake and steps taken to increase vaccination rate. Vaccine 2013; 31(3): 518-23. (PMID: 23174194).

7. Uyeki TM, Bernstein HH, Bradley JS, et al. Clinical practice guidelines by the infectious diseases society of America: 2018 update on diagnosis, treatment, chemoprophylaxis, and institutional outbreak management of seasonal influenza Clinical Infectious Diseases 2019; 68 (10): 1-47. (DOI: 10.1093/cid/ ciy866).

8. Centers for Disease Control and Prevention. National Center for Health Statistics. Weekly updates by select demographic and geographic characteristics;2019. [Internet]. Avaliable from: https://www.cdc. gov/nchs/nvss/vsrr/covid_weekly/index.htm\#AgeAndSex. Accessed: 15.10.2020.

9. Tekin N, Avkan OV. COVID-19 infection in the elderly and people with chronic disease. In: Set T (Ed). Family Medicine and COVID 19 Pandemic. 1th.edition. Turkiye Klinikleri, Turkey 2020 pp.40-8. (in Turkish)

10. Thindwa D, Quesada MG, Liu Y, et al. Use of seasonal influenza and pneumococcal polysaccharide vaccines in older adults to reduce covid-19 mortality. Vaccine 2020; 38 (34): 5398-5401. (PMID: 32600911).
11. Moyo, P., Zullo, A.R., McConeghy, K.W. et al. Risk factors for pneumonia and influenza hospitalizations in long-term care facility residents: A retrospective cohort study. BMC Geriatr 2020; 20 (47): 1-13. (DOI:10.1186/s12877-020-1457-8).

12. B Karakus. Institutional Care for the Elderly in Turkey. In: Bulent Karakus (Ed). Services for elderly, institutional care and status of provinces in Turkey. 1th edition, Ministry of Family and Social Policies Publication, Turkey 2018, pp 126-74. (in Turkish)

13. Zhang $X$, Decker FH, Luo H, et al. Trends in the prevalence and comorbidities of diabetes mellitus in nursing home residents in the United States: 19952004. J Am Geriatr Soc. 2010; 58 (4): 724-30. (PMID: 20398154)

14. Erdogdu HI, Catak B. Influenza, pneumococcal and herpes zoster vaccination rates amongst people aged 65 years and older and related factors. Turkish Journal of Geriatrics 2018;21(4): 498-506. (DOI:10.31086/tjgeri.2018.54). (in Turkish)

15. Baig SA, Hassan M, Ahmed SM, et al. A cross-sectional study to investigate pneumococcal vaccination in the elderly in a low income county: patient knowledge, awareness, and attitudes of vaccination and prevalence rates by socioeconomic status. Hum Vaccin Immunother 2014; 10 (4): 1024-1027. (PMID: 24495898)

16. Kohlhammer $Y$, Schnoor $M$, Schwartz $M$, Raspe $H$, Schäfer T. Determinants of influenza and pneumococcal vaccination in elderly people: a systematic review. Public Health 2007;121 (10): 742-51. (PMID: 17572457).

17. Schneeberg A, Bettinger JA, McNeil S, et al. Knowledge, attitudes, beliefs and behaviours of older adults about pneumococcal immunization, a public health agency of Canada/Canadian institutes of health research influenza research network (pcirn) investigation. BMC Public Health 2014; 14 (442):1-9. (PMID: 24884433).

18. Gazibara T, Kovacevic N, Kisic-Tepavcevic D, et al. Flu vaccination among older persons: Study of knowledge and practices. J Health Popul Nutr. 2019; 38(2):1-9. (PMID: 30606257)

19. Polat $\mathrm{HH}$, Oncel $\mathrm{S}$, Turhan $\mathrm{O}$, et al. Influenza vaccination in 65 and over age adults in Antalya/Turkey. Turkish Journal of Geriatrics 2012; 15 (4): 371-377. (in Turkish)

20. Yigitbasi BA, Satici C, Tanriverdi E, et al. Influenza vaccination frequency and associated factors among 
elderly population, a descriptive study. Turkish Journal of Geriatrics 2018; 21 (4): 490-497. (DOI:10.31086/ tjgeri.2018.53).

21. World Health Organization Regional Office for Europe. Evaluation of seasonal influenza vaccination policies and coverage in the who European region results from the 2008/2009 and 2009/2010 influenza seasons [e-book] World Health Organization Regional Office Publication; 2014. [Internet]. Avaliable from: https://www.euro.who.int/_data/ assets/pdf_file/0003/241644/Evaluation-of-seasonal-influenza-vaccination-policies-and-cover-
age-in-the-WHO-European-Region.pdf. Accessed: 10.09.2020

22. Unal S, Tanriover MD, Tas E et al. The effects of educating family physicians and setting targets for vaccination on pneumococcal vaccination coverage rates. Flora 2015; 20 (1): 10-15. (in Turkish)

23. Ministry of health republic of Turkey. National Vaccine Workshop; 2014. [Internet] Available from: http://www.geriatri.org.tr/pdf/Ulusal_Asi_Calistayi_ Rapor_2014.pdf. Accessed: 04.09.2020. 